\title{
Diabetes mellitus in Swedish middle-aged men
}

\section{The study of men born in 1913 and 1923}

\author{
L.-O.Ohlson ${ }^{1}$, B. Larsson ${ }^{1}$, H.Eriksson ${ }^{2}$, K. Svärdsudd ${ }^{2}$, and L. Welin ${ }^{2}$ and G. Tibblin ${ }^{3}$ \\ ${ }^{1}$ Department of Medicine I, Sahlgrenska Hospital, ${ }^{2}$ Department of Medicine, Östra Hospital and \\ ${ }^{3}$ Department of Family Medicine, University of Uppsala, Sweden
}

Summary. As part of a study of the epidemiology of diabetes mellitus in middle-aged Swedish men, the present paper reports the prevalence and incidence of diabetes and the prevalence of impaired glucose tolerance. Two cohorts of 50-yearold men, representative of the corresponding male population of Gothenburg, Sweden, were examined in 1963 and 1973, respectively, and then followed until 1980. In the cohort of men born in $1913(n=855)$ the diabetes prevalence (WHO criteria), based on a questionnaire and fasting blood glucose, increased from $1.5 \%$ at age 50 to $7.6 \%$ at age 67 . In the cohort of men born in $1923(n=226)$ the prevalence was $3.7 \%$ at age 50 and $4.0 \%$ at age 57 . The overall prevalence of diabetes and impaired glucose tolerance was $25 \%$ among men born in 1913 (age 67) and 18\% among men born in 1923 (age 57). The cumulative risk of developing diabetes from age 50 to 67 was $7.8 \%$. Variables associated with impaired glucose tolerance and newly found diabetes, when degree of obesity was considered, were systolic blood pressure and triglycerides, well known risk factors for both coronary heart disease and diabetes. Uric acid, fasting insulin and glutamic puruvic transaminase, recently discussed as possible risk factors, were also associated with impaired glucose tolerance and newly found diabetes. Thus, both impaired glucose tolerance and newly found diabetes were associated with a clustering of risk factors, not only for diabetes but also for coronary heart disease.

Key words: Diabetes mellitus, epidemiology, prevalence, incidence, impaired glucose tolerance, coronary heart disease, risk factors.
During the last 20 years, several studies on the prevalence of diabetes in various ethnic groups and ages of men and women have been published. Reported prevalence ranges from $0.02 \%[1,2]$ to about $40-50 \%[3,4]$. The highest prevalence has been found in populations that, during one or a few generations, changed their lifestyle fundamentally; i. e. a change in food habits in combination with less physical activity. By such a new lifestyle an earlier hidden, genetic tendency for diabetes seems to have been unmasked [5].

Incidence studies on diabetes in whole populations or representative subsamples [6-11] are few compared to the number of prevalence studies.

Incidence studies (i.e. prospective studies) are more effective than prevalence studies when trying to find risk factors or etiological factors for the development of diabetes [12].

As part of a prospective population study of two cohorts of middle-aged men, the prevalence, incidence, type of treatment and duration of diabetes is presented. Traditional risk factors for coronary heart disease and proposed risk factors for diabetes are analysed in relation to degree of glucose intolerance.

\section{Subjects and methods}

\section{Subjects}

The cross-sectional study

The cohort born in 1913. In 1963 a sample consisting of all men born in 1913 on a date divisible by 3 , still alive at age 50 and living in the city of Gothenburg was drawn from the population register of the city, which by law must be kept up to date. A total of 973 men met these criteria; of these, $855(88 \%)$ men agreed to be examined (Fig. 1). The population has been described in detail elsewhere [13].

In 1967, at 54 years of age, those examined in 1963 were invited to a re-examination in which 792 men (95\% of those still alive) participated.

In 1973 a new sample of 945 men born in 1913 was drawn from the general population using the same criteria as in 1963. Of the 1973 sample $787(83 \%)$ agreed to be examined [14].

In 1980 a third sample of 817 men was selected in the same manner and $644(79 \%)$ were examined.

The cohort born in 1923. In 1973 a sample consisting of all men born in 1923 on the 3rd, 15th or 27th day of each month, and living in the city, was drawn from the general population of Gothenburg. Of the 292 men sampled $226(77 \%)$ participated in the examination [14] (Fig. 1). 


\begin{tabular}{lllll}
\hline & 1913 & \multirow{2}{*}{1923} & \\
\cline { 2 - 3 } & Participants & Non-participants & & \\
\hline 1963 & 855 & 118 & & \\
1967 & 792 & 63 & 226 & 66 \\
1973 & 787 & 158 & 175 & 81 \\
1980 & 644 & 173 & \\
\hline
\end{tabular}

Fig. 1. The number of participants and non-participants in the different cross-sectional studies

\begin{tabular}{|c|c|c|c|c|c|}
\hline & \multicolumn{2}{|l|}{1913} & \multicolumn{3}{|c|}{1923} \\
\hline & Participants & Non-participants & & & \\
\hline \multirow[t]{2}{*}{1963} & 855 & 118 & & & \\
\hline & & drop-outs & & & \\
\hline 1967 & 792 & $46 \uparrow 17$ & & & \\
\hline 1973 & 718 & $\dagger 65$ & 226 & & 66 \\
\hline 1980 & 580 & $111 \dagger 164$ & 164 & 52 & $\$ 10$ \\
\hline
\end{tabular}

$\dagger=$ Number of deaths during follow-up

Fig. 2. The number of participants and non-participants in the longitudinal study. $\dagger=$ number of deaths during follow-up

In 1980 a new sample was drawn from the general population in the same manner as in 1973 . Of the 256 men fulfilling the criteria, $175(68 \%)$ were examined.

Although new samples were drawn from the general population for the cross-sectional studies in 1963, 1973 and 1980 the majority of men participating were the same from examination to examination.

\section{The longitudinal study}

The cohort born in 1913 and initially examined in 1963 was followed up by re-examinations in 1967, 1973 and 1980 (Fig. 2). In 1967, 792 ( $95 \%$ of those still alive) were re-examined. In 1973, $718(94 \%$ of those still alive) were re-examined. In 1980,580 ( $84 \%$ of those participating in 1963 and still alive) were followed up.

The cohort born in 1923 and initially examined in 1973 was followed up in 1980. Of those still alive 164 (76\%) were re-examined (Fig. 2).

\section{The non-participants}

The cohort born in 1913. In 1963, 118 men did not participate in the study. An analysis of this group, including home visits to $40 \mathrm{men}$, was done [15]. Variables relating to diabetes were, however, not included in that protocol.

In order to find men who had developed diabetes and died between two examinations, medical records for those who died during follow-up ( $n=164)$ were scrutinized. Only one man with diabetes who had been missed by the cross-sectional examinations was found.

In 1980,173 men $(21 \%)$ dot not participate in the cross-sectional examination. Of these, 22 men died after sampling but before the examination and 3 men had moved out of town. Five men were chronically hospitalized because of alcoholic or psychiatric diseases. A telephone interview was done with $105(73 \%)$ of the remaining. Nine $(8.9 \%)$ of them stated they had diabetes.

The cohort born in 1923. In 1980, $81(32 \%)$ did not participate in the cross-sectional examination. Of these, 50 men $(62 \%)$ were interviewed by telephone. Three $(6 \%)$ of these stated they had diabetes.

\section{Methods}

\section{Anthropometry}

Body weight and height were measured at all examinations with the subjects wearing undershorts only. Body weight was measured to the nearest $0.1 \mathrm{~kg}$ on a lever balance. Height was measured barefoot to the nearest $1 \mathrm{~cm} \mathrm{[14].}$

Body composition was measured at the examination in 1973 and 1980 and was calculated from total body potassium data and body weight. Body fat was calculated by substracting lean body mass (whole body without adipose tissue mass) from total body weight [14].

Blood pressure was measured at all examinations in the right arm, as casual blood pressure in the seated position after $5 \mathrm{~min}$ rest, using a mercury sphygmomanometer with a cuff size of $12 \times 23 \mathrm{~cm}$.

A family history of diabetes (in 1980) was defined as a positive history of diabetes among first and second degree relatives as given by the participant.

Physical activity during leisure time was scaled from 1-4 [14] where $1=$ sedentary and $4=$ heavy physical activity. The two lowest degrees of physical activity (1 and 2) were counted as low and the two highest ( 3 and 4 ) as high physical activity in this analysis.

Smoking habits were obtained by a questionnaire. For this report the participants were classified as current smokers or non-smokers during the last month.

Treatment for hypertension. Information on medical treatment for hypertension during the last 12 months was obtained by a questionnaire.

Oral glucose tolerance test. In 1973 an oral glucose tolerance test of $100 \mathrm{~g}$ was performed in random subsamples of the men born in 1913 (born on the 6th day of each month) $(n=57)$ and the men born in 1923 (born on the 3rd day of each month) $(n=52)$.

In 1980 an oral glucose tolerance test of $100 \mathrm{~g}$ was performed in $599(93 \%)$ of the men born in 1913 with determination of glucose at zero, $1 \mathrm{~h}$ and $2 \mathrm{~h}$ after loading. A tolerance test of $100 \mathrm{~g}$, instead of $75 \mathrm{~g}$, as recommended by the WHO [16] and the National Diabetes Data Group [17] was performed in order to use the same method as in the examination in 1973. Among the remaining 45 men not participating in the glucose tolerance test, there were 12 diabetic patients. Diabetes status was therefore known for 611 men (95\%). An oral glucose tolerance test was also performed in the same way in $164(94 \%)$ of the men born in 1923.

Blood chemistry. In 1963, 1967 and 1973 fasting blood glucose was determined using the same method. Venous whole blood was taken from an antecubital vein, immediately deproteinized by perchloric acid and analyzed by use of glucose oxidase, peroxidase and O-dianisidine (Reagent from AB Kabi, Stockholm, Sweden) [18]. In 1980, fasting blood glucose was determined by a glucose oxidase method with phenol and 4-amino-phenzone as colour reagent using a Greiner Selective Analyzer (GSA II).

In 1980 biochemical standard methods were used for serum analyses of cholesterol, triglycerides, uric acid, glutamic oxaloacetic transaminase, glutamic pyruvic transaminase and bilirubin. Serum insulin was determined by a double antibody method using a commercially available radioimmunoassay kit (Pharmacia, Uppsala, Sweden).

Glucosuria was tested with urine dip-sticks (Clinistix) after 6-8h of fasting.

The following definitions of glucose tolerance were used: (1) Previously known diabetes mellitus: the diagnosis of diabetes stated by a doctor. (2) Newly found diabetes mellitus: fasting blood glucose > $=7.0 \mathrm{mmol} / 1 \mathrm{and} /$ or $>=10.0 \mathrm{mmol} / 12 \mathrm{~h}$ after an oral glucose tol- 
erance test according to WHO criteria and no previous diagnosis of diabetes. (3) Impaired glucose tolerance: fasting blood glucose < $7.0 \mathrm{mmol} / 1$ and a glucose value $>=7.0-<10.0 \mathrm{mmol} / 12 \mathrm{~h}$ after an oral glucose tolerance test according to WHO criteria. (4) The reference group: those with a normal oral glucose tolerance test (WHO criteria) and no diagnosis of diabetes according to a questionnaire.

\section{Statistical analysis}

The chi-square test was used to test differences in diabetes prevalence between the cohorts born in 1913 and 1923.

In the cohort born in 1913 the reference group, the group with impaired glucose tolerance and the newly found diabetic patients can be regarded as different degrees of glucose intolerance. When regarding previously known diabetic patients as a special group also a time dimension is added, giving a possibility to study complications of diabetes over time in a cross-sectional study. Therefore, trends over the groups were tested. One step included the reference group, the group with impaired glucose tolerance and the group with newly detected diabetic patients. The second step included the group with newly detected diabetic patients and the group with previously known diabetic patients. Pitman's permutation test was used for tests of significance, both as trend test in univariate and bivariate analyses. This is a non-parametric test for both simple correlation and multivariate analysis [19]. The life table curve was constructed by the Kaplan-Meier method [20]. A p value less than 0.05 was considered as statistically significant.

\section{Results}

\section{Prevalence of diabetes mellitus}

The prevalence of diabetes mellitus by age in both cohorts is presented in Figure 3. At age 50, 1.5\% (95\% confidence limits 1.1-2.3) of those born in 1913 had diabetes and at age 67 the prevalence was $7.6 \%$ (5.6-9.6) based on questionnaire and fasting blood glucose. At age 60 an oral glucose tolerance test was performed in a subsample of men $(n=57)$ but no further diabetic patients were found. At age 67 a pathological oral glucose tolerance test was found in another $3.2 \%$ $(1.8-4.6)$, classifying them as new diabetic patients.

In the cohort born in 1923 the prevalence of diabetes at age 50 was $3.7 \%(1.2-6.2)$. There was no significant difference in prevalence at this age compared to those born in 1913. At age 57 a diabetes prevalence of $4.0 \%(1.1-6.9)$ was found which was similar to the prevalence $(5.7 \%)$ found in 60-year-old men in the cohort born in 1913. Furthermore, at age 57 a pathological oral glucose tolerance test was found in $2.4 \%$ (0.1-4.7), fulfilling the criteria for diabetes.

\section{Prevalence of impaired glucose tolerance}

In 1980, a group with impaired glucose tolerance was identified by an oral glucose tolerance test. Among the 67 -year-old men $14.2 \%(11.4-17.0)$ were classified as having impaired glucose tolerance according to WHO criteria. In the cohort of 57-year-old men, impaired glucose tolerance was found in $11.6 \%(6.7-16.5)$.

The distribution of fasting blood glucose in the whole cohort aged 67 years (born in 1913) is presented in Fig-

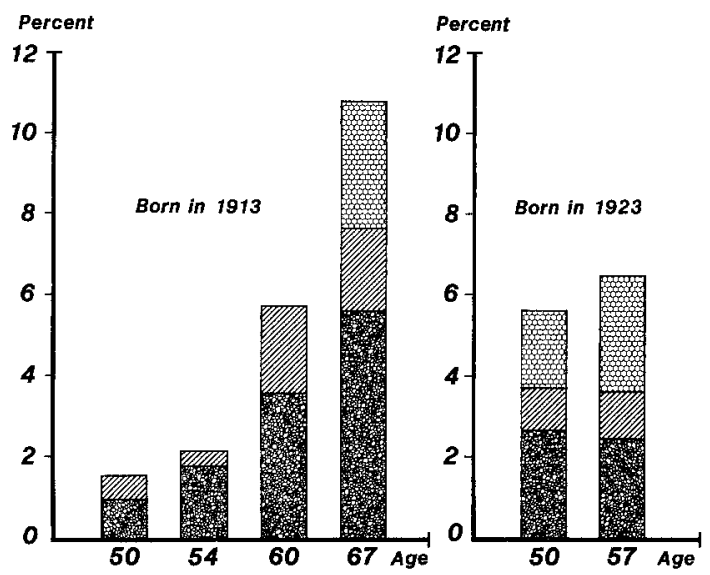

Fig. 3. Prevalence of diabetes mellitus by age in the two cohorts of men born in 1913 and 1923. tolerance test; diabetes newly found by fasting blood glucose; Previously known diabetes

ure 4. The majority (74\%) had a fasting blood glucose $<5.0 \mathrm{mmol} / 1$ and only $5.2 \%$ had a glucose value $>$ $=7.0 \mathrm{mmol} / 1$. In Figure 5 the distribution of fasting blood glucose in the diabetic patients is presented separately. Among the previously known diabetic patients only $59 \%(20 / 34)$ had an elevated fasting blood glucose $(>=7.0 \mathrm{mmol} / 1)$. Those with newly found diabetes were detected by an elevated fasting blood glucose in only $41 \%(13 / 32)$. The rest $(19 / 32,59 \%)$ were identified by a pathological oral glucose tolerance test. The distribution of fasting blood glucose at age 57 (born in 1923), both known and new, were considered together because of small numbers. Only $45 \%(5 / 11)$ of these had a fasting blood glucose $>=7.0 \mathrm{mmol} / 1$.

Glucosuria after an overnight fast was present in $46 \%$ $(16 / 35)$ of those with known diabetes but in only $20 \%$ $(6 / 30)$ of those with newly found diabetes at age 67 . In the younger cohort at age $57,40 \%(2 / 5)$ of those with known diabetes and none of those with newly detected diabetes had glucosuria.

Duration of diabetes was rather short in both cohorts (Table 1). In 1963, among those born in 1913, 75\% $(6 / 8)$ had had diabetes for 10 years or less. In 1980 , $69 \%(25 / 36)$ had had the disease up to 10 years and only $8 \%(3 / 36)$ for more than 20 years. In the cohort born in 1923 the same trend was found.

Type of treatment for diabetes is presented in Table 2. One-fifth to one-third of the diabetic patients were treated with diet only. The proportion treated with oral agents increased with age. At age 67,61\% (22/36) were treated with oral agents. The same trend was found in the younger cohort, where $60 \%(3 / 5)$ were treated with oral agents at age 57 .

Only $11 \%(4 / 36)$ were treated with insulin at age 67 and only one man was using insulin at age 57 . 


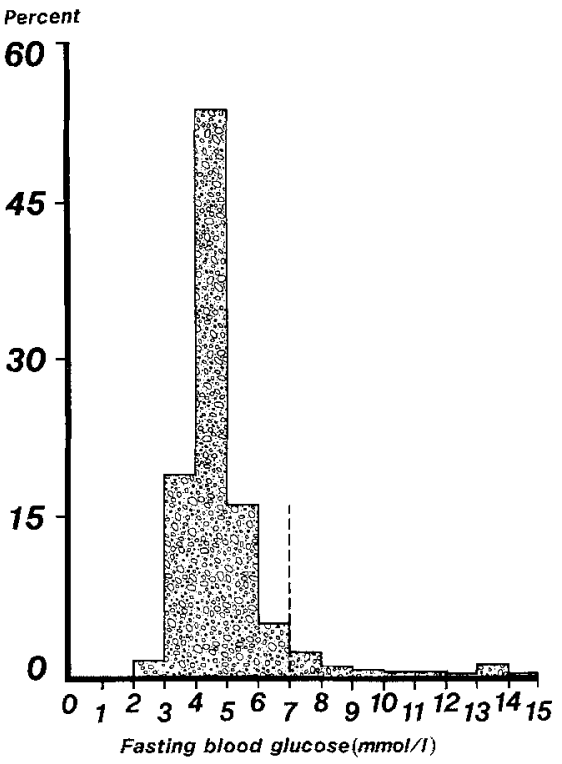

Fig.4. Distribution of fasting blood glucose in the entire cohort of 67-year-old men (born in 1913)

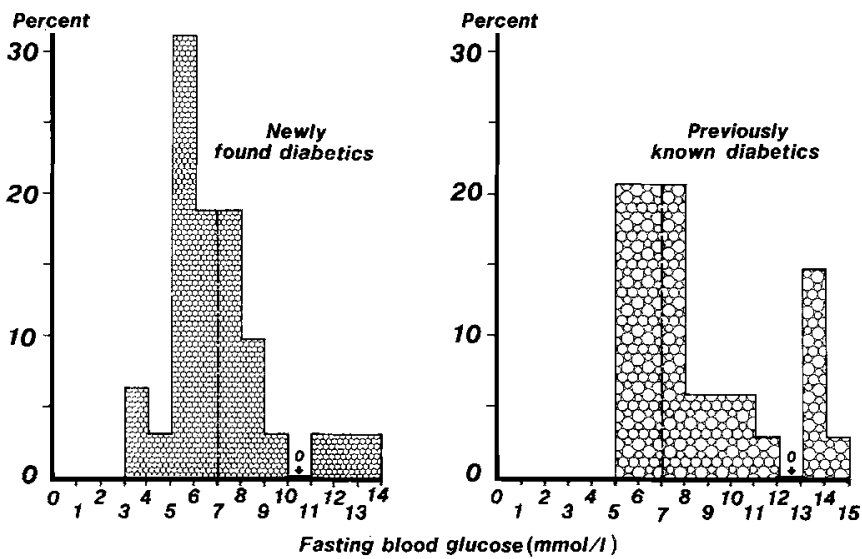

Fig. 5. Distribution of fasting blood glucose in 67-year-old diabetic men (born in 1913)

\section{Risk factors for coronary heart disease and diabetes in 67-year-old men born in 1913 (cross-sectional data)}

By means of an oral glucose tolerance test the cohort of 67-year-old men was divided into four subgroups (WHO criteria): those with impaired glucose tolerance, a group with newly found diabetes, a group with previously known diabetes and a reference group with a normal glucose tolerance.

\section{Univariate analysis}

There was a significantly increasing trend from the reference group to the group with newly found diabetes for a number of conventional risk factors for both coronary heart disease and diabetes. Not only systolic and diastolic blood pressure $(p<0.001)$, triglycerides $(p<$ $0.001)$, body weight $(p<0.001)$ and body fat $(p<0.001)$ increased significantly, but also variables recently dis-
Table 1. Duration of previously known diabetes mellitus at various ages in men born in 1913 and 1923

\begin{tabular}{|c|c|c|c|c|}
\hline \multirow{4}{*}{$\begin{array}{l}\text { Duration } \\
\text { (years) }\end{array}$} & \multicolumn{4}{|l|}{ Age } \\
\hline & \multicolumn{2}{|c|}{ Born in 1913} & \multicolumn{2}{|c|}{ Born in 1923} \\
\hline & \multirow{2}{*}{$\begin{array}{l}50 \\
n(\%)\end{array}$} & 67 & \multirow{2}{*}{$\frac{50}{n(\%)}$} & \multirow{2}{*}{$\frac{57}{n(\%)}$} \\
\hline & & $n \quad(\%)$ & & \\
\hline $0-5$ & $3(37.5)$ & $15(41.7)$ & $4(66.6)$ & $3(60.0)$ \\
\hline $6-10$ & $3(37.5)$ & $10(27.8)$ & $1(16.7)$ & $2(40.0)$ \\
\hline $11-15$ & $1(12.5)$ & $5(13.9)$ & $1(16.7)$ & $0(0)$ \\
\hline $16-20$ & $1(12.5)$ & $3(8.3)$ & $0(0)$ & $0(0)$ \\
\hline$>20$ & $0(0)$ & $3(8.3)$ & $0(0)$ & $0(0)$ \\
\hline Total & $8(100.0)$ & $36(100.0)$ & $6(100.0)$ & $5(100.0)$ \\
\hline
\end{tabular}

Table 2. Type of treatment of previously known diabetes mellitus at various ages in men born in 1913 and 1923

\begin{tabular}{|c|c|c|c|c|}
\hline \multirow{4}{*}{$\begin{array}{l}\text { Type of } \\
\text { treatment }\end{array}$} & \multicolumn{4}{|l|}{ Age } \\
\hline & \multicolumn{2}{|c|}{ Born in 1913} & \multicolumn{2}{|c|}{ Born in 1923} \\
\hline & \multirow{2}{*}{$\begin{array}{l}50 \\
n(\%)\end{array}$} & 67 & \multirow{2}{*}{$\frac{50}{n(\%)}$} & \multirow{2}{*}{$\frac{57}{n(\%)}$} \\
\hline & & $n \quad(\%)$ & & \\
\hline None & $0(0)$ & $1(2.8)$ & $0(0)$ & $0(0)$ \\
\hline Diet only & $2(25.0)$ & $9(25.0)$ & $2(33.3)$ & $1(20.0)$ \\
\hline Oral agents & $3(37.5)$ & $22(61.1)$ & $3(50.0)$ & $3(60.0)$ \\
\hline Insulin & $2(25.0)$ & $4(11.1)$ & 0 & $1(20.0)$ \\
\hline Unknown & $1(12.5)$ & $0(0)$ & $1(16.7)$ & $0(0)$ \\
\hline Total & $8(100.0)$ & $36(100.0)$ & $6(100.0)$ & $5(100.0)$ \\
\hline
\end{tabular}

cussed as possible risk factors like uric acid $(p<0.001)$, fasting insulin $(p<0.001)$ and glutamic pyruric transaminase $(p=0.018)$ (Table 3$)$. A negative association was found for physical activity during leisure time $(p<0.001)$ (Table 4).

Also between the reference group and the group with impaired glucose tolerance a significant increase $(p<0.05)$ was found for all these variables except for glutamic pyruvic transaminase. When comparing the groups with newly found and previously known diabetes there was a significantly negative association for insulin at $60 \mathrm{~min}(p=0.007)$ and uric acid $(p<0.001)$. There was also a positive association for a family history of diabetes $(p=0.017)$.

Treatment for hypertension was common in all subgroups. As hypertensive drugs could affect many of the variables presented, especially blood pressure and uric acid a subdivision into those treated for hypertension and those not treated was made for all four subgroups of glucose tolerance (Table 5). For each subgroup blood pressure for those treated for hypertension was higher except for those with newly found diabetes. Also uric acid was increased among those with hypertension, but the trend with increasing uric acid from the reference group to those with newly found diabetes presented in Table 1 remained in this subdivision. Also the negative association for uric acid between newly 
Table 3. Means and standard deviations (SD) for various possible risk factors for coronary heart disease and diabetes mellitus in 67 -year-old men in relation to degree of glucose intolerance

\begin{tabular}{|c|c|c|c|c|c|c|c|c|c|c|}
\hline & \multicolumn{2}{|c|}{$\begin{array}{l}\text { Reference } \\
\text { group } \\
(n=458)\end{array}$} & \multicolumn{2}{|c|}{$\begin{array}{l}\text { Impaired } \\
\text { glucose } \\
\text { tolerance } \\
(n=85)\end{array}$} & \multicolumn{2}{|c|}{$\begin{array}{l}\text { Newly found } \\
\text { diabetes }\end{array}$} & \multirow{2}{*}{$\begin{array}{l}\text { Reference-Im- } \\
\text { paired glucose } \\
\text { tolerance-newly } \\
\text { found diabetes } \\
p\end{array}$} & \multicolumn{2}{|c|}{$\begin{array}{l}\text { Previously } \\
\text { known } \\
\text { diabetes } \\
(n=36)\end{array}$} & \multirow{2}{*}{$\begin{array}{l}\text { Newly found } \\
\text { diabetes - } \\
\text {-previously } \\
\text { known diabetes } \\
p\end{array}$} \\
\hline & Mean & (SD) & Mean & (SD) & Mean & (SD) & & Mean & $(\mathrm{SD})$ & \\
\hline $\begin{array}{l}\text { Systolic blood pressure } \\
(\mathrm{mmHg})\end{array}$ & 152.1 & $(22.7)$ & 162.7 & $(24.1)$ & 168.1 & $(23.6)$ & $<0.001$ & 160.1 & $(23.2)$ & NS \\
\hline Cholesterol (mmol/l) & 6.7 & (1.3) & 6.6 & $(1.0)$ & 6.9 & (1.5) & NS & 6.8 & $(1.7)$ & NS \\
\hline Triglycerides $(\mathrm{mmol} / \mathrm{l})$ & 1.6 & $(0.9)$ & 1.9 & $(0.8)$ & 2.4 & (1.6) & $<0.001$ & 2.9 & $(4.5)$ & NS \\
\hline Uric acid (mmol/l) & 344 & $(77)$ & 369 & (96) & 390 & $(86)$ & $<0.001$ & 298 & (94) & $<0.001$ \\
\hline $\begin{array}{l}\text { Glutamic oxaloacetic } \\
\text { transaminase (ukat/l) }\end{array}$ & 0.52 & $(0.21)$ & 0.51 & $(0.13)$ & 0.53 & $(0.12)$ & NS & 0.60 & $(0.43)$ & NS \\
\hline Bilirubin (umol/l) & 9.2 & $(3.8)$ & 8.7 & $(2.8)$ & 9.4 & $(4.0)$ & NS & 9.3 & (3.3) & NS \\
\hline Insulin $0^{\prime}(\mathrm{m} \mathrm{U} / \mathrm{l})$ & 12.7 & (8.4) & 15.0 & (9.1) & 21.9 & $(22.6)$ & $<0.001$ & 14.9 & $(10.3)$ & NS \\
\hline Insulin $60^{\prime}(\mathrm{mU} / 1)$ & 76.5 & $(46.1)$ & 85.8 & $(59.3)$ & 76.9 & $(63.1)$ & NS & 40.9 & $(29.0)$ & 0.007 \\
\hline Height $(\mathrm{cm})$ & 174.7 & $(5.7)$ & 174.3 & $(6.3)$ & 173.3 & (5.5) & NS & 175.8 & $(5.8)$ & NS \\
\hline Body weight $(\mathrm{kg})$ & 76.5 & $(10.6)$ & 79.2 & $(9.8)$ & 81.6 & $(10.9)$ & $<0.001$ & 78.8 & $(12.2)$ & NS \\
\hline $\begin{array}{l}\text { Body mass index } \\
\left(\mathrm{kg} / \mathrm{m}^{2}\right)\end{array}$ & 25.1 & $(3.2)$ & 26.0 & (2.9) & 27.2 & (3.6) & $<0.001$ & 25.4 & $(3.0)$ & 0.031 \\
\hline Body fat (kg) & 23.2 & $(8.6)$ & 26.7 & $(6.5)$ & 26.8 & $(7.2)$ & $<0.001$ & 26.3 & $(10.5)$ & NS \\
\hline
\end{tabular}

$\mu \mathrm{kat} / 1=\frac{\mathrm{U}}{60}$

Table 4. Percentage of some possible risk factors for cardiovascular disease and diabetes mellitus in 67-year-old men in relation to degree of glucose intolerance

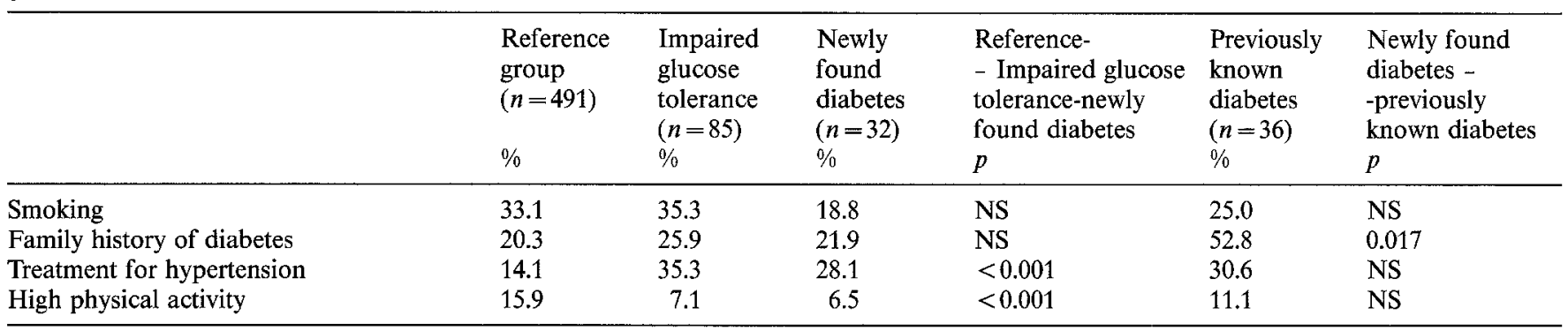

found diabetic patients and previously known diabetic patients remained among those treated for hypertension.

\section{Bivariate analysis}

Most risk factors for both coronary heart disease and diabetes are associated with obesity. Therefore, body fat, as a measurement of obesity, was accounted for in a bivariate analysis. The increasing trend from the reference group to the group with newly found diabetes for both systolic blood pressure $(p<0.001)$, triglycerides $(p<0.001)$, uric acid $(p<0.001)$, fasting insulin $(p<0.001)$ and glutamic pyruvic transaminase $(p<$
0.005) remained significant when body fat was accounted for. When comparing those with newly found diabetes and previously known diabetes the negative trend for uric acid $(p<0.001)$ and insulin at $60 \mathrm{~min}$ $(p<0.01)$ remained significant as well as the positive trend for a family history of diabetes $(p=0.029)$.

\section{Longitudinal data}

The cumulative risk of diabetes by age in the cohort born in 1913 is presented in Figure 5 using the life table technique, including not only the survivors but also the diabetic patients who died during follow-up. 
Table 5. Means for blood pressure, uric acid and body mass index in 67-year-old men in relation to degree of glucose intolerance, subdivided into those treated for hypertension (HT) and those without treatment (non-HT)

\begin{tabular}{|c|c|c|c|c|c|c|c|c|}
\hline & \multicolumn{2}{|c|}{$\begin{array}{l}\text { Reference } \\
\text { group }\end{array}$} & \multicolumn{2}{|c|}{$\begin{array}{l}\text { Impaired glucose } \\
\text { tolerance }\end{array}$} & \multicolumn{2}{|c|}{$\begin{array}{l}\text { Newly found } \\
\text { diabetes }\end{array}$} & \multicolumn{2}{|c|}{$\begin{array}{l}\text { Previously known } \\
\text { diabetes }\end{array}$} \\
\hline & $\begin{array}{l}\text { Non-HT } \\
(n=422) \\
\text { mean }\end{array}$ & $\begin{array}{l}\text { HT } \\
(n=69) \\
\text { mean }\end{array}$ & $\begin{array}{l}\text { Non-HT } \\
(n=55) \\
\text { mean }\end{array}$ & $\begin{array}{l}\mathrm{HT} \\
(n=30) \\
\text { mean }\end{array}$ & $\begin{array}{l}\text { Non-HT } \\
(n=23) \\
\text { mean }\end{array}$ & $\begin{array}{l}\text { HT } \\
(n=9) \\
\text { mean }\end{array}$ & $\begin{array}{l}\text { Non-HT } \\
(n=25) \\
\text { mean }\end{array}$ & $\begin{array}{l}\text { HT } \\
(n=11) \\
\text { mean }\end{array}$ \\
\hline Systolic blood pressure (mm Hg) & 150 & 161 & 159 & 170 & 170 & 162 & 154 & 175 \\
\hline Diastolic blood pressure $(\mathrm{mm} \mathrm{Hg}$ ) & 82 & 91 & 84 & 91 & 89 & 87 & 82 & 93 \\
\hline
\end{tabular}

\section{Cumulative Risk (\%)}

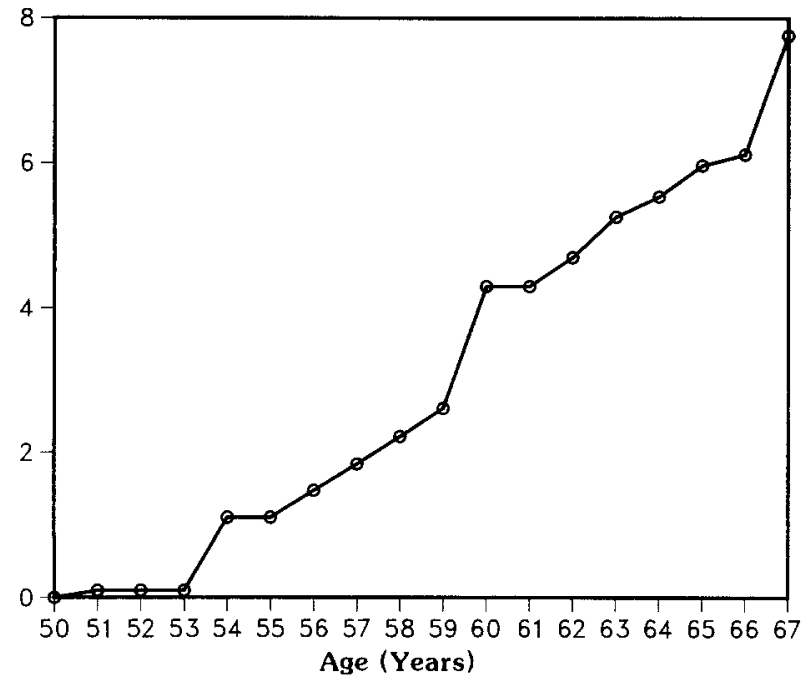

Fig. 6. Cumulative risk of developing diabetes mellitus from age 50 in the cohort born in 1913

During age 51-67 years 7.8\% developed diabetes. The annual incidence for ages 51-60 years was $4.3 / 1000$ population and for ages $61-67$ years $4.9 / 1000$ population.

\section{Discussion}

As expected, a trend towards higher prevalence of diabetes was found among living non-participants than among participants. Many diabetic patients already have a regular medical contact and might therefore be less interested in participating in surveys of this kind. Since diabetic patients have an increased risk of dying from cardiovascular disease [21], they could also be lost by selective mortality during follow-up.

This trend was found in the present study [22], where mortality among those having diabetes at baseline was almost doubled during 17 years of follow-up as compared to non-diabetic subjects. This means that those diabetic patients developing the most severe vascular disease have already died and can not be included in our cross-sectional data.
Most earlier Scandinavian studies report prevalence of diabetes from younger ages or several ages considered together [23-25]. In a prospective Icelandic study of men aged $34-62$ years, $1.8 \%$ had known diabetes after 7.5 years of follow-up [10]. From another survey of cardiovascular disease in Norway the diabetes prevalence in men aged 35-49 years differed from $5.2 / 1000$ to $10.0 / 1000$ in different counties [26]. In a Swedish cross-sectional study of two cohorts of men the prevalence of diabetes according to a questionnaire was $0.9 \%$ at age 50 and increased to $4.8 \%$ at age 60 . From these cross-sectional data the annual incidence for ages $50-60$ was estimated to $3.9 / 1000$ [27]. In a recent Swedish study the prevalence of diabetes for men aged $47-54$ years were $1.3 \%$ [28].

There are fewer prospective studies presenting the incidence of diabetes in a population of middle-aged men examined on at least two different occasions [6-11]. In Table 6 a number of these studies are presented. In the Israel Study [7] the incidence was about twice as high as in the present study, but in the Israel Study the cohort was a mixture of ethnic groups with various genetic and environmental backgrounds resulting in different incidences in the subgroups.

When trying to compare results from different studies, one must be aware that different criteria for diabetes have been used. Since the National Diabetes Data Group criteria were proposed in 1979 and were adopted with some changes by the WHO in 1980 and in 1985 [29], comparisons have become easier. For example, in the Rochester study report from 1983 [8] revised data were used, i.e. the National Diabetes Data Group criteria were applied, reducing the incidence of diabetes with amost $20 \%$ compared to the results with earlier definitions.

In the present study another $14.2 \%$ of those aged 67 years and another $11.6 \%$ of those aged 57 years were classified as having impaired glucose tolerance according to WHO criteria. When using only medical records, questionnaires or testing for glucosuria there is a risk of underestimating the frequency of the disease [30]. By using both fasting blood glucose and oral glucose tolerance tests the prevalence in 67-year-old men in the present study was doubled compared to using only questionnaire data. With these methodologic 
Table 6. Incidence of diabetes mellitus in middle-aged men in a number of population studies

\begin{tabular}{|c|c|c|c|c|}
\hline $\begin{array}{l}\text { Refer- } \\
\text { ence }\end{array}$ & $\begin{array}{l}\text { Investigators } \\
\text { and years of } \\
\text { report }\end{array}$ & Population & $\begin{array}{l}\text { Age } \\
\text { (years) }\end{array}$ & $\begin{array}{l}\text { Annual inci- } \\
\text { dence rate } \\
\text { per } 1000 \\
\text { population }\end{array}$ \\
\hline 7 & $\begin{array}{l}\text { Medalie et al. } \\
\text { (1978) }\end{array}$ & $\begin{array}{l}\text { Israel Ischae- } \\
\text { mic Heart Dis- } \\
\text { ease Project (Is- } \\
\text { rael) }\end{array}$ & $\begin{array}{l}50-59 \\
60\end{array}$ & $\begin{array}{l}10.0 \\
11.2\end{array}$ \\
\hline 6 & $\begin{array}{l}\text { Butler et al. } \\
\text { (1982) }\end{array}$ & $\begin{array}{l}\text { Tecumseh } \\
\text { (USA) }\end{array}$ & $55-$ & 4.4 \\
\hline 11 & $\begin{array}{l}\text { Wilson et al. } \\
\text { (1981) }\end{array}$ & $\begin{array}{l}\text { Framingham } \\
\text { (USA) }\end{array}$ & $\begin{array}{l}50-59 \\
60-\end{array}$ & $\begin{array}{l}5.9 \\
4.3\end{array}$ \\
\hline 8 & $\begin{array}{l}\text { Melton et al. } \\
\text { (1983) }\end{array}$ & $\begin{array}{l}\text { Rochester } \\
\text { (USA) }\end{array}$ & $\begin{array}{l}50 \\
60 \\
70\end{array}$ & $\begin{array}{l}2.5 \\
5.2 \\
7.0\end{array}$ \\
\hline 9 & $\begin{array}{l}\text { Papoz et al. } \\
(1982)\end{array}$ & $\begin{array}{l}\text { Paris Pros- } \\
\text { pective Study } \\
\text { (France) }\end{array}$ & $43-54$ & 5.4 \\
\hline \multirow[t]{2}{*}{10} & $\begin{array}{l}\text { Sigurdsson } \\
\text { et al. (1981) }\end{array}$ & (Iceland) & $43-61$ & 1.3 \\
\hline & $\begin{array}{l}\text { The present } \\
\text { study }\end{array}$ & (Sweden) & $\begin{array}{l}51-60 \\
61-67\end{array}$ & $\begin{array}{l}4.3 \\
4.9\end{array}$ \\
\hline
\end{tabular}

difficulties in mind the incidence rate in the present study seems to be in accordance with others, taking the increasing risk of diabetes by age into consideration.

We used an oral glucose tolerance test of $100 \mathrm{~g}$ and not the $75 \mathrm{~g}$ recommended by the WHO and the NDDG. This might to some extent affect the 2-h glucose value [31]. However, in an elderly cohort like ours the difference between $75 \mathrm{~g}$ and $100 \mathrm{~g}$ seems to be of minor importance [32]. There are other factors, perhaps of greater importance, that also might affect the glucose levels, i. e. differences in body weight both within and between populations. The WHO criteria propose two abnormal glucose values for the clinical diagnosis of diabetes or impaired glucose tolerance. In epidemiological studies, however, this is often difficult to perform and the use of a single abnormal glucose value is therefore accepted [17, 33].

The possibility to detect groups with an increased risk of coronary heart disease and/or diabetes with a single glucose tolerance test was evaluated in 67-yearold men. Those with impaired glucose tolerance are known to have an excess risk of developing diabetes $[34,35]$. Recently, an excess risk of coronary heart disease associated with impaired glucose tolerance had also been discussed [36-38]. Our cross-sectional data also showed an increased number of risk factors for both diabetes and coronary heart disease in the impaired glucose tolerance as well as among the newly detected diabetic patients. The possibility of a common risk factor or a clustering of risk factors for both diabetes and coronary heart disease has been proposed [39].
Variables associated with impaired glucose tolerance and a newly found diabetes, when degree of obesity was considered, were systolic blood pressure and triglycerides, well known risk factors for both coronary heart disease and diabetes. Uric acid, associated with development of diabetes in the Israel Study [40], fasting insulin associated with coronary heart disease in the Helsinki Policemen Study [41], and glutamic pyruvic transaminase associated with development of diabetes in our own longitudinal study (unpublished observations) were also associated with impaired glucose tolerance and/or newly found diabetes in the present study.

Among the previously known diabetic patients a decreasing trend for several risk factors was seen, probably reflecting the effect of intervention. A family history of diabetes was, however, more common in this group and is probably explained not only by increased genetic susceptibility for diabetes but also by better information about family history.

The degree of physical activity during leisure time decreased with impairment of glucose tolerance $(p<$ 0.001). This might reflect differences in life style and changing life style in the population would be one way of preventing the development of diabetes. These findings were not confirmed in the Whitehall Study [42].

\section{Conclusion}

In this study of randomly selected middle-aged men of an urban population, there was a five-fold increase of diabetes from 50 to 67 years of age. Almost all diabetic patients had Type 2 (non-insulin-dependent) diabetes. The majority were treated with oral agents and had suffered from the disease for less than 10 years. Only $59 \%$ of those with previously known diabetes and only $41 \%$ of those with newly detected diabetes at 67 years of age had an elevated fasting blood glucose indicating that the degree of hyperglycaemia, as expected, was limited in this population based cohort.

When both diabetes and impaired glucose tolerance were considered together, about one-fourth of the men aged 67 and $18 \%$ of those aged 57 had an abnormal glucose tolerance according to WHO criteria.

Factors associated with impaired glucose tolerance and newly found diabetes, when degree of obesity was considered, were systolic blood pressure and triglycerides, well known risk factors for both coronary heart disease and diabetes. Uric acid, fasting insulin and glutamic puruvic transaminase, recently discussed as possible risk factors, were also associated with impaired glucose tolerance and/or newly found diabetes. Thus both impaired glucose tolerance and newly found diabetes were associated with a clustering of risk factors not only for diabetes but also for coronary heart disease. 
Acknowledgements. This study was supported by grants from the Swedish Medical Research Council (B86-27X-06276-05) the Gothenburg Medical Society, the Swedish Diabetes Association, the King Gustav V and Queen Victoria's Foundation and the Gothenburg University.

\section{References}

1. Mouratoff CJ, Carroll NV, Scott EM (1969) Diabetes mellitus in Arthapascan Indians in Alaska. Diabetes 18: 29-32

2. Sagild U, Littauer J, Jespersen CS, Andersen S (1966) Epidemiological studies in Greenland 1962-64. Acta Med Scand 179: 29-39

3. Bennett PH, Burch TA, Miller M (1971) Diabetes mellitus in American (Pima) indians. Lancet 2: 125-128

4. Zimmet P, Guinea A, Taft P, Guthrie W, Thoma K (1976) The high prevalence of diabetes mellitus on a pacific island. Diabetologia 12: 428

5. Zimmet $\mathbf{P}$ (1982) Type 2 (non-insulin-dependent) diabetes - an epidemiological overview. Diabetologia 22: 399-411

6. Butler WJ, Ostrander Jr LD, Carman WJ, Lamphiear DE (1982) Diabetes mellitus in Tecumseh, Michigan. Prevalence, incidence and associated conditions. Am J Epidemiol 116: 971-980

7. Medalie JH, Herman JB, Goldbourt U, Papier CM (1978) Variations in incidence of diabetes among 10000 adult Israeli males and the factors related to their development. Adv Metab Disorders 9: 93-110

8. Melton III, LJ, Palumbo PJ, Chu C-P (1983) Incidence of diabetes mellitus by clinical type. Diabetes Care 6:75-86

9. Papoz L, Eschwege E, Warnet I-M, Richard J-L, Claude J-R (1982) Incidence and risk factors of diabetes in the Paris Prospective Study (G R E A). In: Eschwege E (ed) Advances in diabetes epidemiology, INSERM Symp No 22. Elsevier Biomedical Press, Amsterdam, pp 113-122

10. Sigurdsson $\mathrm{G}$, Gottskálksson $\mathrm{G}$, Thorsteinsson $T$, Davidsson D, Olafsson O, Samuelsson S, Sigfusson N (1981) Community screening for glucose intolerance in middle-aged Icelandic men. Acta Med Scand 210: 21-26

11. Wilson PW, McGee DL, Kannel WB (1981) Obesity, very low lipoproteins, and glucose intolerance over fourteen years. The Framingham Study. Am J Epidemiol 114: 697-704

12. West KM (1978) Epidemiology of diabetes and its vascular lesions. Elsevier, New York, 127-158

13. Tibblin G (1967) High blood pressure in men aged 50 - A population of men born in 1913. Acta Med Scand [Suppl] 479

14. Larsson B (1978) Obesity. A population study of men, with special reference to development and consequences for the health. Ph D Thesis, University of Gothenburg

15. Tibblin G (1965) A population study of 50-year-old men. An analysis of the non-participation group. Acta Med Scand 178: 453-459

16. WHO Expert Committee on Diabetes Mellitus (1980) Second Report. WHO Tech Rep Ser No 646

17. National Diabetes Data Group (1979) Classification and diagnosis of diabetes mellitus and other categories of glucose intolerance. Diabetes 23: 1039-1057

18. Levin K, Linde S (1962) Determination of glucose in blood, cerebrospinal fluid and urine with a new glucose oxidase reagent. Svenska Läkartidningen 59: 3016-3026

19. Bradley J (1968) Distribution-free statistical tests. Prentice-Hall, London, pp 68-86

20. Kaplan EL, Meier P (1958) Nonparametric estimation from incomplete observations. J Am Stat Assoc 53: 457-481

21. Kannel WB, McGee DL (1979) Diabetes and cardiovascular risk factors. The Framingham Study. Circulation 59: 8-13

22. Ohlson L-O, Svärdsudd K, Welin L, Eriksson H, Wilhelmsen L, Tibblin G, Larsson B (1986) Fasting blood glucose and risk of coronary heart disease, stroke, and all-cause mortality: a 17-year follow-up of men born in 1913. Diabet Med 3: 33-37

23. Grönberg A, Larsson T, Jung J (1967) Diabetes in Sweden. A clinicostatistical, epidemiological and genetic study of hospital patients and death certificates. Acta Med Scand [Suppl] 477: $1-275$

24. Jorde R (1962) The diabetes survey in Bergen, Norway 1956. An epidemiological study of blood sugar values related to sex, age and weight. Norwegian University Press, Bergen-Oslo

25. Nilsson SE, Lindholm $\mathrm{H}$, Bülow $\mathrm{S}$, Frostberg $\mathrm{N}$, Emilsson $\mathrm{T}$, Stenkula G (1964) The Kristianstad survey 1963-1964. Studies in normal adult population for variation and correlation in some clinical anthropometric and laboratory values, especially the peroral glucose tolerance test. Acta Med Scand [Suppl] 428: 1-54

26. Bjarvett K, Foss OP, Gjervig T (1983) The cardiovascular disease study in Norvegian counties. Acta Med Scand [Suppl] 675: 1-184

27. Waern U (1977) Findings at a health survey of 60-year-old men and recorded disease during their preceding 10 years of life. $\mathrm{PhD}$ Thesis, University of Uppsala

28. Cederholm J, Wibell L (1985) Glucose intolerance in middleaged subjects - a cause of hypertension? Acta Med Scand 217: 363-371

29. Diabetes mellitus. Report of a WHO Study Group (1985) Tech Rep Ser No 727

30. National Health Interview Surveys (1978) Diabetes data compiled 1977. Publication No (NIH) 78-1468. US Department of Health, Education and Welfare, Washington DC

31. West KM (1978) Epidemiology of diabetes and its vascular lesions. Elsevier, New York, 75-80

32. Toeller M, Knusmann R (1973) Reproducibility of oral glucose tolerance tests with three different loads. Diabetologia $9:$ 102-107

33. Teuscher A, Jarrett RJ (1984) Diabetes mellitus: diagnostic criteria. Diabet Med 1: 305-307

34. Keen H, Jarrett RJ, McCartney P (1982) The ten-year follow-up of the bedford survey (1962-1972) Glucose tolerance and diabetes. Diabetologia 22: $25-30$

35. King H, Zimmet P, Raper LR, Balkau B (1984) The natural history of impaired glucose tolerance in the Micronesian population of Nauru: a six-year follow-up study. Diabetologia 26:39-43

36. Stamler R, Stamler J (1979) Asymptomatic hyperglycemia and coronary heart disease. J Chronic Dis 32: 829-837

37. Fuller JH, Shipley MJ, Rose GA, Jarrett RJ, Keen H (1983) Mortality from coronary heart disease and stroke in relation to degree of glycaemia. The Whitehall Study. Br Med J 287: 867-870

38. Barrett-Connor E, Wingard DL, Criqui MH, Suarez L (1984) Is borderline hyperglycemia a risk factor for cardiovascular death? J Chronic Dis 37: 773-779

39. Jarrett RJ (1984) Type 2 (non-insulin-dependent) diabetes mellitus and coronary heart disease - chicken, egg or neither? Diabetologia 26: $99-102$

40. Herman JB, Goldbourt U (1982) Uric acid and diabetes: observations in a population study. Lancet $2: 240-243$

41. Pyörälä K (1979) Relationship of glucose tolerance and plasma insulin to the incidence of coronary heart disease. Results from two population studies in Finland. Diabetes Care 2: 131-141

42. Jarrett RJ, Shipley MJ, Hunt R (1986) Physical activity, glucose tolerance, and diabetes mellitus: the Whitehall Study. Diabet Med 3: 549-551

Received: 26 November 1986

and in revised form: 13 April 1987

Dr. L.-O.Ohlson

Department of Medicine I

Sahlgrenska Hospital

S-41345 Gothenburg

Sweden 